\title{
The Global Status Report on Violence Prevention 2014: Where to for the South African health sector?
}

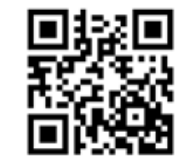

The World Health Organization (WHO), the United Nations Development Programme and the United Nations Office on Drugs and Crime jointly released the first Global Status Report on Violence Prevention ${ }^{[1]}$ on 10 December 2014. The report reviews how governments around the world, including in South Africa (SA), are attempting to curb interpersonal violence.

There is some good news in the report. In common with many other countries, SA's homicide rate has declined over the past decade: it was $40.3 / 100000$ in 2004/5, and 32.2/100 000 in 2012/2013. ${ }^{[2]}$ Across the five types of interpersonal violence assessed in the report child maltreatment, youth violence, intimate partner violence, sexual violence and elder abuse - SA has national action plans for all but two, namely youth violence and elder abuse (and in these two cases, some provinces have action plans).

But manifestly it is not all good news. Homicide levels in SA are fluctuating around $32 / 100000$, and over the past 4 years, the lowest level achieved was $30.9 / 100000$ (in 2011/2012). ${ }^{[2]}$ Homicide is a robust indicator of the prevalence of other forms of violence, ${ }^{[3,4]}$ so this demonstrates that $\mathrm{SA}$ is struggling to reduce violence below the horizon achieved in 2011/2012. That rate is in itself exceedingly high: in 2012, the African Region as a whole had a rate of 10.9/100 000, making SA one of the most lethally violent African countries for which data are available. ${ }^{[1]}$

This is a health sector issue for several reasons. First, the injuries and deaths caused by interpersonal violence place a considerable burden on the health sector. Second, evidence-based public health approaches to preventing violence are increasingly demonstrating their effectiveness. ${ }^{[1,3,5]}$ The Global Status Report on Violence Prevention addresses several key areas for violence prevention: action plans, laws and policies, prevention programmes and services for victims of violence, and data on violence, and the SA health sector has a role to play in each.

There are two key policy-level public health interventions that are likely to reduce all forms of violence: limiting access to firearms and to alcohol. ${ }^{[1,3]}$

In terms of firearms control, SA has a comprehensive legal system in place to restrict firearm proliferation and misuse. However, recent experiences of trauma surgeons (A Nicol, A B van As, oral communication, 22 October 2014) and high-profile firearm murders suggest that firearm homicides are increasing after an initial drop. ${ }^{[6]}$ In March 2015, the SA parliament will initiate a national Firearm Summit to review the state of the country's firearm controls with a view to improving them. ${ }^{[7]}$ This review will need evidence - evidence best obtained through injury surveillance in trauma centres and mortuaries. With the National Non-Natural Mortality Surveillance System ${ }^{[8]}$ we are well placed to record deaths due to firearms: we now urgently need surveillance of injuries across trauma centres to complete the picture, as injuries tend to be more frequent than deaths and so provide a more complete picture of the role of firearms in violence. ${ }^{[9]}$

Alcohol control geared towards reduction presents a more complicated picture, especially with SA's history of alcohol abuse dating back to colonial times. ${ }^{[10]}$ The government taxes most forms of alcohol in order to discourage excessive consumption. Nonetheless, a large proportion of South Africans binge drink, which carries a number of possible serious health consequences, including an increased risk of being both a perpetrator and a victim of violence. ${ }^{[1]}$ There is a plethora of policy-level interventions that can reduce this, such as increasing taxes on alcohol and restricting hours of sale, and collaboration between health professionals, law enforcement and communities to develop and implement appropriate policies, as well as treatment and prevention programmes. ${ }^{[11]}$ Most recently, Minister of Health Aaron Motsoaledi is to be commended for his call for a ban on alcohol advertising: ${ }^{[12]}$ the rest of the health sector should support him in this.

SA laws to prevent interpersonal violence are progressive and comprehensive in most areas. The only gaps are laws providing for victim compensation and legal representation, and in the area of child maltreatment, prevention (such as banning female genital mutilation, and a comprehensive ban on corporal punishment). ${ }^{[1]}$ But the real problem is lack of enforcement. At best our laws are only partially enforced, and most are applied in a very limited way. ${ }^{[1]} \mathrm{A}$ case in point is the banning of corporal punishment in schools: data from national surveys conducted by the Centre for Justice and Crime Prevention (CJCP) reveals that $49.8 \%$ of SA children still suffer corporal punishment at the hands of teachers. ${ }^{[13]}$ Violence in schools has serious consequences for children, including increasing the likelihood that they will go on to commit violent acts. ${ }^{[14]}$ Health professionals, such as educational psychologists, urgently need to roll out evidence-based programmes to provide teachers with skills for non-violent discipline. Of course, it takes considerable resources to implement large-scale interventions, but countries with similar circumstances to SA, such as Brazil, Colombia, El Salvador, Mexico and India, are faring much better in this regard. ${ }^{[1]}$

Similarly, there are a number of violence prevention programmes across the country that address each form of violence and services for victims, but these are typically provided in a very limited way and not on the large scale that can meaningfully address the problem. Notable exceptions include programmes that train children to recognise and avoid sexually abusive situations, preschool enrichment programmes, life-skills training for young people, and anti-bullying policies. ${ }^{[1]}$ However, an investigation 10 years ago found that youth violence prevention programmes in SA were typically not evidence based and had not been rigorously evaluated, ${ }^{[15]}$ and a more recent survey of parenting programmes had similar findings, ${ }^{[16]}$ suggesting that there is not yet a culture of evidence-based intervention and evaluation in prevention programming in SA. There is therefore very little to give us confidence that programmes implemented here are effective - yet globally there is mounting evidence about effective programmes that could be applied in SA. ${ }^{[5]}$

In addition, SA's victim services are less developed in comparison with countries with similar challenges of violence in the Americas and South-East Asia. ${ }^{[1]}$ This too needs attention, within the health sector and elsewhere. Supporting victims can prevent them both from becoming victims again and from becoming perpetrators. ${ }^{[17,18]}$

If policies and programmes are to be effective, they need to be driven by relevant and accurate data. Compared with most other low- to middle-income countries, SA is data rich, and has national statistics on youth violence, intimate partner violence and sexual violence. ${ }^{[1]}$ A survey that will give us the first-ever nationally representative data on child maltreatment is in progress, and is being led by researchers at CJCP and the University of Cape Town and funded by the UBS Optimus Foundation. These data will be released 
in mid-2015, and have massive potential to inform the design and delivery of interventions to reduce child maltreatment where they are needed the most. Elder abuse, however, remains under-researched in SA (as in many other countries). We need to continue to uphold these high standards, and expand on and use the data we have to design evidence-based interventions.

Reducing violence is of course important from a human rights and safety perspective, but it will also contribute to national development.

First, violence costs the economy a great deal. Patching up injuries, physical rehabilitation, conducting autopsies, treating mental health problems, prosecuting and incarcerating perpetrators, and putting children in foster care are all enormously costly things to do. According to a recent report from KPMG Human and Social Services, violence against women in SA alone costs the economy between R28.4 and R42.2 billion per year - $0.9-1.3 \%$ of the gross domestic product. ${ }^{[19]}$ That would build many, many houses, and one of the recommendations of the Global Status Report on Violence Prevention is good housing design to reduce concentrated poverty, an area in which SA is failing. ${ }^{[1]}$

Second, violence prevention programmes typically do not only prevent violence but also promote other good outcomes. Parenting programmes that aim to reduce child maltreatment, for instance, not only reduce child abuse and neglect but also teach parents the skills that promote child wellbeing more broadly. From the prevention perspective, their children are less likely to use drugs, to become HIVpositive, or to begin lives of crime. From the promotion perspective, their children are more likely to stay in school, and to have the skills to hold down a job and hence to contribute to the economy. ${ }^{[2]}$

Reducing violence should therefore be a national priority, both to promote the rights of citizens to lives free from fear, and to release more funding for national development. Violence prevention initiatives that follow the public health approach can be effective. Since early calls to take this approach, ${ }^{[21]}$ SA has established a solid foundation of relevant data and policy. Now is the time to build on this base by acting on the World Health Assembly Resolution ${ }^{[2]}$ passed earlier this year, and implement the recommendations of the World Report on Violence and Health, ${ }^{[3]}$ namely:

- Create, implement and monitor a national action plan for violence prevention.

- Enhance capacity for collecting data on violence.

- Define priorities for, and support research on, the causes, consequences, costs and prevention of violence.

- Promote primary prevention responses.

- Strengthen responses for victims of violence.

- Integrate violence prevention into social and educational policies, and thereby promote gender and social equality.

- Increase collaboration and exchange of information on violence prevention.

- Promote and monitor adherence to international treaties, laws and other mechanisms to protect human rights.
- Seek practical, internationally agreed responses to the global drugs trade and the global arms trade.

\section{Catherine L Ward}

Department of Psychology, Faculty of Humanities, University of Cape Town, South Africa, and Safety and Violence Initiative, University of Cape Town

\section{Guy Lamb}

Safety and Violence Initiative, University of Cape Town, South Africa

Corresponding author: C L Ward (catherine.ward@uct.ac.za, cathy.ward.sa@gmail.com)

1. World Health Organization. Global Status Report on Violence Prevention 2014. Geneva: WHO, 2014. (SA profile p. 195.) http://www.undp.org/content/dam/undp/library/corporate/Reports/UNDP-GVAviolence-2014.pdf (accessed 17 December 2014)

2. South African Police Service. Crime Categories: Figures and Ratios. Pretoria: South African Police Service, 2014. http://www.saps.gov.za/resource_centre/publications/statistics/crimestats/2014/crime_ stats.php (accessed 17 December 2014).

3. Krug E, Dahlberg L, Mercy J, Zwi A, Lozano R. World Report on Violence and Health. Geneva: World Health Organization, 2002.

4. Matzopoulos R, Bhalla K, Harrison J. Homicide. In: Donnelly PD, Ward CL, eds. The Oxford Textbook of Violence Prevention: Epidemiology, Evidence and Policy. Oxford: Oxford University Press, 2015:11-18. Donnelly PD, Ward CL, eds. The Oxford Textbook of Violence Prevention: Epidemiology, Evidence and Policy. Oxford: Oxford University Press, 2015.

6. Matzopoulos RG, Thompson ML, Myers JE. Firearm and nonfirearm homicide in 5 South African cities: A retrospective population-based study. Am J Public Health 2014;104(3):455-460. [http://dx.doi. org/10.2105/AJPH.2013.310650]

7. Merrington Z. Parliament to host gun control summit next year [television broadcast]. South African Merrington Z. Parliament to host gun control
Broadcasting Corporation, 6 November 2014.

8. Butchart A, Peden M, Matzopoulos R, et al. The South African National Non-Natural Mortality Butchart A, Peden M, Matzopoulos R, et al. The South African National Non-Natural
Surveillance System - rationale, pilot results and evaluation. S Afr Med J 2001;91(5):408-417.

Surveillance System - rationale, pilot results and evaluation. S Afr Med J 2001;91(5):408-417.
9. Schuurman N, Cinnamon J, Matzopoulos R, Fawcett V, Nicol A, Hameed SM. Collecting injury surveillance data in low- and middle-income countries: The Cape Town Trauma Registry pilot. Glob Public Health 2011;6(8):874-889. [http://dx.doi.org/ 10.1080/17441692.2010.516268]

10. Mager A. 'White liquor hits black livers': Meanings of excessive liquor consumption in South Africa in the second half of the twentieth century. Soc Sci Med 2004;59(4):735-751. [http://dx.doi.org/ doi:10.1016/j.socscimed.2003.12.005

11. Parry $\mathrm{CDH}$, Dewing S. A public health approach to addressing alcohol-related crime in South Africa. Afr J Drug Alcohol Stud 2006;5(1):41-56.

12. Makuyana I. Motsoaledi says no alcohol adverts. The New Age [newspaper on the Internet], 12 September 2013. http://www.thenewage.co.za/106998-1056-53-Motsoaledi_says_no_alcohol_ adverts/?switcher $=1$ (accessed 17 December 2014).

3. Burton P, Leoschut L. School Violence in South Africa: Results of the 2012 National School Violence Study. Cape Town: Centre for Justice and Crime Prevention, 2013.

14. Souverein F, Ward CL, Visser I, Burton P. Serious, violent young offenders in South Africa: Are they life-course persistent offenders? I Interpers Violence (in press).

15. Farr V, Dawes A, Parker Z. Youth violence prevention and peace education programmes in South Africa: A preliminary investigation of programme design and evaluation practices. Cape Town: Children's Institute, University of Cape Town, 2003

16. Wessels IM. Child maltreatment prevention programmes in South Africa: Investigating design and evaluation practices. MA thesis. Cape Town: University of Cape Town, 2012.

17. Hawkridge S, Berg A, Seedat S. The consequences of violence: Mental health issues. In: Donnelly PD, Ward CL, eds. The Oxford Textbook of Violence Prevention: Epidemiology, Evidence and Policy. Oxford: Oxford University Press, 2015:97-104

18. Feder G, Sardinha L. Preventing intimate partner violence thorugh advocacy and support programmes. In: Donnelly PD, Ward CL, eds. The Oxford Textbook of Violence Prevention: Epidemiology, Evidence and Policy. Oxford: Oxford University Press, 2015:193-200.

19. KPMG Human and Social Services. Too costly to ignore - the economic impact of gender-based violence in South Africa Jol Services. Too costly to ig

violence in South Africa. Johannesburg: KPMG, 2014. Behav 2002;27(6):951-976. [http://dx.doi.org/10.1016/S0306-4603(02)00298-8]

21. Kruger J, Butchart A, Seedat M, Gilchrist A. A public health approach to violence prevention in South Africa. In: Van Eeden R, Wentzel M, eds. The Dynamics of Aggression and Violence in South Africa. Pretoria: Human Sciences Research Council, 1998:399-424.

22. World Health Organization. Resolution WHA67.15. Strengthening the role of the health system in addressing violence, in particular against women and girls, and against children. 67th World Health Assembly, Geneva, 19-24 May 2014. Documentation WHA67: main documents, information documents, diverse documents, resolution. Geneva: WHO, 2014.

S Afr Med J 2015;105(3):183-184. DOI:10.7196/SAMJ.9305 